\title{
O CUIDAR DO CLIENTE COM PROBLEMAS HEMATOLÓGICOS - UMA EXPERIÊNCIA DE ENSINO-APRENDIZAGEM
}

\author{
THE CARE OF PATIENTS WITH HEMATOLOGICAL PROBLEMS - A \\ TEACHING AND LEARNING EXPERIENCE \\ EL CUIDADO DEL CLIENTE CON PROBLEMAS HEMATOLÓGICOS - UNA \\ EXPERIENCIA DE ENSEÑANZA-APRENDIZAJE
}

Mauro Leonardo Salvador Caldeira dos Santos'

\begin{abstract}
RESUMO: O presente trabalho discute a experiência de alunos do Curso de Graduação em Enfermagem da Escola de Enfermagem da Universidade Federal Fluminense, com o cuidado a clientes com problemas hematológicos e como apreendem formas de incorporarem o aprendizado de vivências em situaçöes como a morte e emoçōes advindas do sofrimento causado pelas doenças crônicas. Destaca a importância desses conteúdos na formação reflexiva dos alunos para possibilitar uma compreensão critica na atuação do estágio supervisionado.
\end{abstract}

PALAVRAS-CHAVE: problemas hematológicos, aprendizagem, cuidado, enfermagem

\section{INTRODUÇÄO}

A idéia principal para o desenvolvimento desse estudo deu-se na prestação de cuidados a clientes com problemas hematológicos por alunos do $5^{\circ}$ periodo do Curso de Graduação da Escola de Enfermagem da Universidade Federal Fluminense, em seu estágio supervisionado na Disciplina de Enfermagem Médico-Cirúrgica I, realizado em um Hospital Universitário.

No decorrer das atividades, os professores observaram uma gama de reações emocionais manifestadas pelos alunos no ato de prestação do cuidado, que variavam entre ansiedade, insegurança, choro, tristeza, enfim, reações em relaçăo a dor, à frustração da perda, já que a morte era uma constante, devido ao tipo de doença dos clientes ali internados (linfomas e leucemias).

Faz-se importante lembrar que nesta disciplina os alunos iniciam o cuidado integral ao cliente, isto é, começam a se inserir no cenário da prática, onde suas vivências do cotidiano e sua experiência pessoal sofrem impacto ao deparar com o sofrimento do cliente com problemas hematológicos (leucemias e linfomas).

Com isso o objetivo enquanto professores da disciplina é de oferecer ao aluno a oportunidade de prestar cuidado ao cliente hematológico, proporcionando perspectivas outras no aprendizado da assistência, problematizando as questôes que surgem durante o estágio supervisionado seja no momento do cuidado ou durante as supervisões técnicas onde os casos são discutidos e aprofundados, na tentativa do conhecimento de si como aluno e futuro enfermeiro e das formas como o cliente reage a doença.

Pensamos que o enfoque principal dentro de cada tendência pedagógica deve nos permitir refletir sobre cada etapa de construção do aprendizado. Segundo Moraes citado por Pettengillet et al. (1998) "examinar a critica, analisá-la sob diferentes ângulos em que é proposta e buscar

' Professor Assistente do Depto de Enfermagem Médico Cirúrgica da UFF/RJ. Doutor em Filosofia da Enfermagem-UFSC. 
sua superação: esta é a tarefa mais complexa".

Há também a identificação profissional com a representação social da Enfermagem centrada na figura do Enfermeiro e o seu trabalho no Hospital. O aluno na medida em que troca informaçōes e conhecimentos sobre o fazer da Enfermagem altera a sua percepção da realidade profissional que muitas vezes é diferente do que ele imaginava. Como cita Padilha (1990), "O ensino muitas das vezes é fragmentado e discordante da prática, e os objetivos educacionais são inadequados às atividades desempenhadas pelas enfermeiras nos serviços de saúde. Ao aluno năo é dada oportunidade de questionar e discutir sobre a sua açăo, sendo cobrados rigidamente, quanto à postura e disciplina, além da carga horária extensa."

Diante desses fatos tracei alguns objetivos a serem alcançados para o entendimento dessas questões, a fim de que os alunos tenham um desempenho menos sofrivel na construção do processo de aprendizagem do cuidar.

O objetivo apresentado foi:

-Analisar as dificuldades dos alunos em relação ao cuidado dos clientes com problemas hematológicos;

\section{METODOLOGIA}

Utilizou-se a metodologia de pesquisa qualitativa, que facilitou abordar o problema de forma mais completa, propiciando traçar as demandas dos alunos aos professores e as dificuldades que advinham com os clientes com problemas hematológicos.

A pesquisa descritiva, de acordo com Lakatos e Marconi (1985) está interessada em "descobrir e observar fenômenos, procurando descrevê-los, classificá-los e interpretá-los. Normalmente è utilizada para pesquisar atitudes, observar procedimentos, descobrir tendências. reconhecer interesses e valores, etc."

Os sujeitos do estudo foram alunos que já haviam cursado a disciplina de Enfermagem Médico-Cirúrgica I no $5^{\circ}$ periodo, ou seja, já cursavam o $6^{\circ}$ ou $7^{\circ}$ periodos, totalizando 30 (trinta) alunos.

Nosso interesse se deu no campo prático, onde os alunos permaneciam em Enfermarias de Clínica Médica, masculina e feminina, do Hospital Universitário Antônio Pedro da Universidade Federal Fluminense. A escolha recaiu sobre a Enfermaria de Hematologia, que contém quatro leitos femininos e quatro leitos masculinos, onde se encontram clientes internados com diagnósticos de leucemias e linfomas. A Enfermaria tem como caracteristica ser isolada por divisórias, com varanda e banheiros próprios, proporcionando uma maior privacidade.

Os dados foram coletados através de um formulário com perguntas, que versavam sobre a experiência em cuidar dos clientes com problemas hematológicos e como esta contribuiu para a vida profissional dos alunos.

O método será a análise de conteúdo de acordo com os critérios da abordagem qualitativa. Para Bogdane Berlen citado por Ludke e André (1986), "a pesquisa qualitativa envolve a obtenção de dados descritivos, obtidos no contato direto do pesquisador com a situação estudada ....". É uma técnica que se dirige para o estudo das idéias e năo das palavras isoladamente.

A análise de conteúdo tem como intenção a inferência como pontua Bardin (1991) quando diz que "a inferência de conhecimentos relativos às condições de produção (ou, eventualmente, de recepção), inferência esta que recorre $a$ indicadores (quantitativos ou não)."

Os dados foram analisados a partir do conteúdo escrito nos formulários, visando uma melhor compreensão dos fatos envolvidos na relação do aluno com o cliente com problemas hematológicos e os conflitos advindos desta relação.

Como num trabalho preliminar, foram traçadas categorias a partir da análise de conteủdo proposta por Bardin (1991), articulando a representação destes com a vivência dos alunos na prática do cuidar. Muitos discursos, além de serem expressivos, foram marcados também pelo 
O cuidar do cliente com problemas hematológicos...

não-dito das emoções.

A partir da análise do conteúdo dos formulários foram construidas três categorias :

- Elaboração do sofrimento pela biologização da doença

- As vivências da dor para o amadurecimento no cuidar

- A idealização e renegação da morte

\section{ANÁLISE E COMENTÁRIOS}

\section{ELABORAÇÃO DO SOFRIMENTO PELA BIOLOGIZAÇĀO DA DOENÇA.}

A primeira categoria levantada foi em relação à experiência em cuidar de clientes hematológicos que se caracteriza pela influência na elaboração da cientificidade da doença. Neste sentido os sentimentos se configuraram da seguinte forma:

Devido ao bom conhecimento das doenças hematológicas antes do contato com os clientes, contribuiu para prestar uma boa assistência de Enfermagem (Aluno 06).

Porque tomei conhecimento e pesquisei as doenças hematológicas mais comuns (Aluno 2)

O estudo anterior ao estágio ajudou muito a entender os distúrbios hematológicos e diminuir a minha ansiedade (Aluno 22).

Os alunos colocam que a partir do entendimento biológico da doença a experiência se torna menos angustiante, afastando de certa forma o deparar com o real da dor e da morte. $O$ que parece oportuno nesta descoberta é a importância da caracterização da nosologia. Dentre as várias criticas que se encontram como a influência do modelo biomédico, que no caso as disciplinas do conteúdo biomédico torna-se uma sustentação para o enfrentamento da problemática. Como cita Olievenstein (1989) "O acaso, o afetivo, o emocional agudos não têm lugar a não ser que passem pelo moinho de um reducionismo asséptico."

\section{AS VIVÊNCIAS DA DOR PARA O AMADURECIMENTO NO CUIDAR.}

Numa segunda categoria, a das "vivências", baseada no conteúdo teórico dado no $5^{\circ}$ periodo, o que poderia parecer precoce - o contato com a morte, o cuidado de clientes com tratamentos invasivos, por vezes transformadores da imagem corporal.

Foi comovente e ao mesmo tempo estimulante. Comovente pelo estado do cliente, pelas intercorrências que haviam, pelo seu sofrimento. Estimulante por poder ver de perto a luta pela vida (ele ver melhora quando na verdade está piorando) e a satisfação do cliente com o trabalho prestado ao mesmo. O retorno é gratificante (Aluno 18).

Bastante triste, mas válida a experiência, principalmente por uma questão de amadurecimento (Aluno 25).

Pelas respostas dos alunos entendemos que a experiência foi considerada proveitosa pelos alunos, pois permite que se faça uma ponte do conhecimento técnico-científico e a problematização das açőes de Enfermagem junto a esses clientes. Percebe-se que os alunos alcançaram um amadurecimento diante das situaçōes limites, o que poderá traduzir uma formação profissional satisfatória como Enfermeiros. 
Segundo Costa (1977) "A sociedade espera do profissional de Saúde o papel de 'salvador'. Por essas razões, os alunos entram geralmente na escola com essa expectativa de si, reforçados pela filosofia profissional de Enfermagem, centrando nos aspectos da manutenção da vida e pelas exigências técnicas, acabam por criar em torno de si uma fantasia de onipotência."

\section{A IDEALIZAÇÃO E NEGAÇÃO DA MORTE.}

Numa terceira categoria, em que se trata das experiências do cuidar e das situaçōes ocorridas durante o estágio, os mecanismos de idealização e renegação da morte são exaltados nos discursos dos alunos.

Um cliente se mostrava saturado de tantos exames que deviam ser realizados ... e não queria deixar ninguém chegar perto dele ... entendi sua situação e procurei convencê-lo com uma conversa longa. Ele chorou e quase chorei também. Ao final da conversa ... me agradeceu a atençäo que dei a ele (Aluno 03).

No começo foi difícil, pois olhava para o cliente com sentimento de pena ... notei que a minha pena não iria ajudá-lo, mas sim o meu desempenhar em minhas funções, o que procurei fazer da melhor maneira possivel (Aluno 20).

Os alunos relatam a necessidade de humanizar o cuidar, refletir sobre a sua vida, ou que acharam dificil e traumática até o evitamento da questäo do "cansaço" em cuidar destes clientes. O contato com a morte gera sentimentos de impotência nos alunos, em momentos acarretando com isso um certo distanciamento como forma de diminuição da ansiedade e auto preservação.

Em seu trabalho sobre a idealizaçäo da morte Anna Wetham citada por Mannoni(1985) coloca de maneira esclarecedora os efeitos de seu seminário sobre os que o assistem (estudantes de Medicina, enfermeiros). No primeiro caso, assistem-se debates livres e animados; no segundo caso é o evitamento à exposição a sua questão que domina.

A mesma autora afirma ainda "o que a surpreendeu foi a maneira como os enfermeiros se sentiam 'gratificados' por poderem exercer uma função de "nursing" dos clientes no fim da vida., quando falam de seus doentes, fazem-no num contexto emocional intenso."

\section{CONSIDERAÇÕES FINAIS}

Nestes trinta formulários avaliados podemos preliminarmente compreender que a experiência do cuidar do cliente com problemas hematológicos leva o aluno de graduação à necessidade de buscar uma compreensão maior dos valores éticos da vida e que o aprendizado teórico de alguma forma anterior ao cenário da prática, diminui ansiedades e dificuldades na abordagem do cuidado ao cliente.

Além disso, a importância da introdução de disciplinas das ciências humanas para o amadurecimento das questöes limites com que a enfermagem lida no cotidiano do cuidado, como por exemplo dar conta de uma multiplicidade de experiências do cuidado que visam a mais extrema singularidade.

Com efeito, de maneira a tirar dessas experiências, fatores como tomada de decisões que determinem a habilidade no manuseio das técnicas e articular a confiança em si e formas de construção que permitam aos alunos a inclusão de reflexöes sobre a sua prática e as fontes geradoras de ansiedades na assistência aos clientes com problemas hematológicos.

A rigor, essas práticas pedagógicas e compreensão do fenômeno educacional nos fez pensar que a preparação de individuos para o exercicio de uma profissão como a enfermagem siga em direção da autonomia para que se opere uma transformação nos fazeres, alcançando 
um processo ativo de construção do ensino-aprendizado.

ABSTRACT: This study presents the experience of a group of students of the nursing graduation course at the Fluminense Federal University regarding the care of patients with hematological problems. It shows how these students deal with the death and suffering when contacting patients with chronic diseases The investigation also aims at indicating how important these matters are for student's reflexive and critical development during their training period.

KEYWORDS: hematological problems, learning, care, nursing

RESUMEN: El presente trabajo discute una experiencia de los alumnos del Curso de Graduación de Enfermeria de la Escuela de Enfermeria de la UFF, que trata del cuidado a clientes con problemas hematológicos y como dichos alumnos aprenden formas de incorporar lo aprendido mediante experiencias, tales como la muerte y las emociones provenientes del sufrimiento causado por las enfermedades crónicas. Se destaca la importancia de esos contenidos en la formación reflexiva de los académicos, para que ello les posibilite una comprensión critica en su forma de actuar durante las prácticas supervisadas.

PALABRAS CLAVE: problemas hematológicos, aprendizaje, cuidado, enfermeria

\section{REFERÊNCIAS BIBLIOGRÁFICAS}

BARDIN, L. Análise de conteúdo. São Paulo: Edições 70, 1991.

COSTA, L.A. Situações vida-morte. Participação do Enfermeiro.1977. Dissertaçāo (Mestrado)- Escola de Enfermagem Anna Nery - UFRJ, Rio de Janeiro.

LAKATOS, E. M e MARCONI, M. Fundamentos de metodologia cientifica. São Paulo: Atlas, 1985.

LUDKE, M; ANDRÉ, M. Pesquisa em educação: abordagens qualitativas. São Paulo:EPU, 1986.

MANNONI, M. O nomeável e o inominável. A última palavra da vida. Rio de Janeiro: Zahar, 1995.

OLIEVENSTEIN, C. O năo-dito das emoções. Rio de Janeiro: Zahar, 1989.

PADILHA, M. I. C. S. O Resgate das raizes- A influência da formação familiar e social na escolha e exercicio da enfermagem. 1990. Tese (Livre Docência) - Faculdade de Enfermagem-UNI-RIO,Rio de Janeiro. 